\title{
Stable carbon isotopes in tree rings of beech: climatic versus site-related influences
}

\begin{abstract}
Stable carbon isotopes in tree rings are a promising tool in palaeoclimate research, provided attempts are made to disentangle climatic from local effects (e.g. soil properties, competition, light). The ${ }^{13} \mathrm{C} / 12 \mathrm{C}$ variations in cellulose of tree rings of beech (Fagus sylvatica) were determined at several sites in the Swiss Central Plateau covering the last 50 years. We chose sites which differ in moisture conditions and sampled cores from four to six trees per site. The mean ${ }^{13} \mathrm{C} /{ }^{12} \mathrm{C}$ series from the different dry sites (distant by up to $40 \mathrm{~km}$ ) are closely interrelated suggesting a common external cause. Correlation analysis with climate data proved the total precipitation in the months May, June and July to have the strongest effect on the carbon isotopes $(r=-0.73)$. This result is in agreement with the commonly used model which relates the isotope discrimination to the water use efficiency. On the other hand, the isotope series of the wet sites are not as well correlated to the climate. At two of the sites (a dry and a humid) tree ring width suddenly increased. We used this effect as a test-case to study the influence of local growth conditions on the climate-isotope relationship.
\end{abstract}

Key words Stable carbon isotopes • Palaeoclimate • Fagus sylvatica $\cdot$ Tree ring $\cdot$ Precipitation

\section{Introduction}

Tree rings are a precisely datable archive of organic material and contain valuable information about the growth

M. Saurer $(\bullet) \cdot$ R. Siegwolf

Paul Scherrer Institute, CH-5232 Villigen PSI, Switzerland

\section{S. Borella}

Physics Institute, University of Berne, Sidlerstrasse 5, CH-3012 Berne, Switzerland

\section{F. Schweingruber}

Swiss Federal Institute for Forest, Snow and Landscape Research, CH-8903 Birmensdorf, Switzerland conditions at the time when a tree ring is formed. Tree ring width and late-wood density have been widely used for climatic reconstruction but their application appears to be mainly restricted to sites where a single factor dominates growth (Schweingruber 1988). For instance, temperature is the dominant factor determining growth for trees near the northern timber line, and accordingly August temperature in these areas can be readily reconstructed with dendrochronological methods (Briffa et al. 1988). Stable carbon isotopes in tree rings offer a promising new tool to extend this approach. Originally, ${ }^{13} \mathrm{C} / 12 \mathrm{C}$ ratio variations in cellulose of tree rings were analysed to reconstruct the time course of ${ }^{13} \mathrm{C} / 12 \mathrm{C}$ in atmospheric $\mathrm{CO}_{2}$ (Tans and Mook 1980). Soon, it was discovered that isotope fractionation processes during the uptake of $\mathrm{CO}_{2}$ by the trees interfere with this purpose, and climatic or local effects have been suggested to be the cause for ${ }^{13} \mathrm{C} /{ }^{12} \mathrm{C}$ variations. Correlations mainly with precipitation and temperature have been found (e.g. Leavitt and Long 1988; Lipp et al. 1991; Tans and Mook 1980) and it appears feasible to use isotope variations for climate reconstruction. However, this approach is not straight-forward because several factors influence the carbon isotope fractionation at the same time. In particular, it is not clear to what extent site conditions such as water and nutrient availability disturb the climatic signal. For example, it could be shown that at relatively dry sites the $\delta^{13} \mathrm{C}$ in tree rings of beech provides information about the precipitation amount in summer, whereas the $\delta^{13} \mathrm{C}$ hardly correlates with precipitation at humid sites (Saurer et al. 1995a).

This can be understood by considering the underlying processes which determine the carbon isotope discrimination between atmospheric $\mathrm{CO}_{2}$ and plant matter. According to the Farquhar et al. (1982) model for $\mathrm{C}_{3}$-plants, it is - as a first approximation - the $\mathrm{CO}_{2}$ concentration in the intercellular spaces of the leaf (ci) which determines the discrimination, and ci is influenced by both the stomatal conductance and by the photosynthetic capacity. A large variety of external factors can influence ci and hence $\delta^{13} \mathrm{C}$ in plant matter. Moisture conditions of the soil as well as the relative humidity of the atmosphere have a relatively 


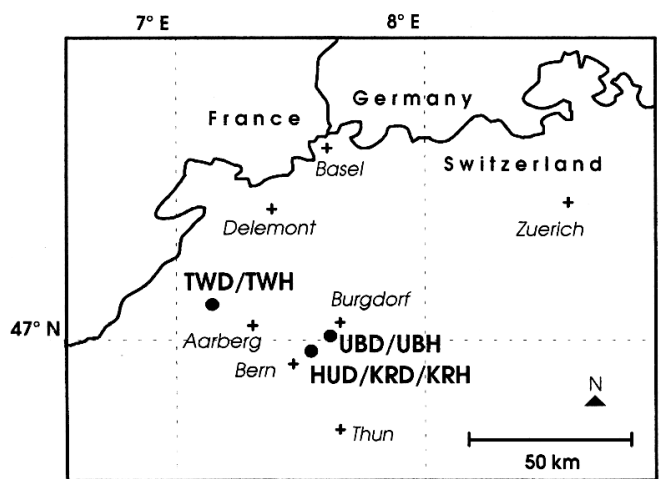

Fig. 1 Map of the study area indicating the tree sites $(\mathbf{O})$ and the meteorological stations $(+)$

direct impact on the stomatal apparatus. In a summer with little precipitation the stomata will be more closed in the long run than in a wet summer and ci will be relatively low because the $\mathrm{CO}_{2}$ supply through the stomata is limited. According to the Farquhar-equation this will result in increased $\delta^{13} \mathrm{C}$ values. Yet, this mechanism only holds as long as water is a limiting factor, and therefore the local growth conditions have to be taken into account.

A possible approach to disentangle local from climatic effects may be the combined analysis of tree ring width and isotope variations. Therefore, we address the following question in this study. Is there a correlation between tree ring width and the carbon isotope ratio and, if so, which environmental causes are responsible for such an effect? We analysed beech trees from a dry and a humid site on the southern and the northern slope of a valley in Switzerland where a sudden increase of tree ring width occurred. This event provided a test-case to study the influence of local growth conditions on the climate-isotope relationship. We compared the results from these two sites with data from other sites where no such increase in ring width took place and discuss the findings in the context of the problem of obtaining climatological information from $\delta^{13} \mathrm{C}$ in tree rings.

\section{Materials and methods}

\section{Site description}

The study area is situated in the Swiss Central Plateau (see Fig. 1). Climate is temperate-moist: the mean annual precipitation is typically around $1000 \mathrm{~mm}$ and the mean annual temperature is approximately $9{ }^{\circ} \mathrm{C}$. The highest precipitation rates are found in June, July and August with values above $100 \mathrm{~mm}$. A dry site (Unterbergental Dry = UBD) and a humid site (Unterbergental Humid $=\mathrm{UBH}$ ) are situated close together (distance $200 \mathrm{~m}$ ) on opposite sides of a small valley. The dry site is on the southern slope and the humid site is on the northern slope. The valley extends from north-east to south-west $(600 \mathrm{~m}$ a.s.1.) and is bordered by wooded hills (approximately $700 \mathrm{~m}$ a.s.l.). The precipitation at the two locations is the same, but due to the differing light exposition the soil moisture conditions and plant community between the sites vary. Tree species at UBH are Fagus sylvatica and Abies alba with a few Picea abies (Milio-Fagetum), and F. sylvatica, Pinus sylvestris and Picea abies at UBD (Lugulo silvaticae-Fagetum typi- cum; Ellenberg and Kloetzli 1972). Another relatively humid site (Krauchthal Humid $=\mathrm{KRH})$ and a dry site (Krauchthal Dry $=$ KRD) were selected at a distance of approximately $7 \mathrm{~km}$. The trees at the KRD site (Seslerio-Fagetum) grow on shallow, sandy soil on top of a sandstone rock (well drained), the trees at KRH (Pulmonario-Fagetum) grow on deep, loamy soil on a steep slope exposed to the north-west. The sites HUD (Hub Dry), TWD (Twann Dry) and TWH (Twann Humid) have been described in Saurer et al. (1995a). The investigated species at all sites is beech ( $F$. sylvatica).

\section{Tree ring sampling}

Four to six beech trees per site were selected. Care was taken to use only trees that apparently had similar growth conditions (adult trees of similar height and exposition to light, grown in an area smaller than $50 \mathrm{~m} \times 50 \mathrm{~m})$. At the beginning of the investigated period (1934) no tree was younger than 30 years, therefore the juvenile effect (Francey and Farquhar 1982) possibly can be excluded. With an increment borer we took two cores per tree from opposite sides of the stem at a height of approximately $1.5 \mathrm{~m}$. The cores were carefully dated and cut into pieces including three tree rings each with a sharp blade. We combined three rings to yield enough material and to reduce processing time. The investigated period is from 1934 to 1990 for the sites UBD, UBH, HUD, from 1934 to 1987 for TWD and TWH, from 1964 to 1990 for $\mathrm{KRH}$, and from 1970 to 1990 for KRD. The analysis was performed in 1 year resolution for KRD and KRH but only 3 year means are presented in this study. The samples were milled and cellulose was extracted from the wood (Brenninkmeijer 1983). Ring width was measured on separate cores using a semi-automated system (Swiss Federal Institute of Forest, Snow and Landscape Research, Birmensdorf).

\section{Determination of the isotope ratios}

We measured individual $\delta^{13} \mathrm{C}$ series for every tree except for the sites HUD, KRD, KRH where we pooled the samples from four trees before the $\delta^{13} \mathrm{C}$ analysis. Variations of isotope ratios are expressed in $\delta$ notation, i.e. the relative deviation from the PDB-standard is given:

$$
\delta^{13} \mathrm{C}=\left[\frac{\left({ }^{13 \mathrm{c}} / 12_{\mathrm{C}}\right) \text { Sample }}{\left(13_{\mathrm{C}} / 12_{\mathrm{C}}\right) \mathrm{PDB}}-1\right] \times 1000 \%
$$

Our continuous flow measurement system comprises an elemental analyser which is coupled to an isotope ratio mass-spectrometer (Finnigan MAT, delta S). The elemental analyser (EA 1108, Fisons, Italy) consists of an autosampler, a combustion tube at $1020^{\circ} \mathrm{C}$ containing the catalysts chromium oxide and silvered cobaltous-cobaltic oxide, a reduction tube at $650{ }^{\circ} \mathrm{C}$ containing copper granules, a water trap (magnesium perchlorate), and a gas chromatographic column (Poropak QS, $40^{\circ} \mathrm{C}$ ). The samples are loaded into tin capsules and dropped into the combustion tube under a helium gas stream. Simultaneously, a pulse of oxygen is injected which results in a flash combustion of the tin capsule and the sample $\left(1700^{\circ} \mathrm{C}\right)$. The catalysts in the combustion tube guarantee a complete combustion. In the reduction tube excess oxygen is removed and nitrogen oxides are reduced to $\mathrm{N}_{2}$ (for samples containing nitrogen). The combustion products $\mathrm{H}_{2} \mathrm{O}, \mathrm{N}_{2}$ and $\mathrm{CO}_{2}$ are swept by the helium carrier gas through the water trap, then through the GC column which separates $\mathrm{N}_{2}$ and $\mathrm{CO}_{2}$, and then reach the mass-spectrometer. The standard deviation of $\delta^{13} \mathrm{C}$ for the repeated analysis of commercial cellulose is $0.1 \%$.

\section{Results}

Isotope data of individual trees

The $\delta^{13} \mathrm{C}$ values of tree ring cellulose from the humid site UBH are in the range from $-26 \%$ o to $-25 \%$ o between 1935 and 1977 (Fig. 2, lower graph), with the exception of one 


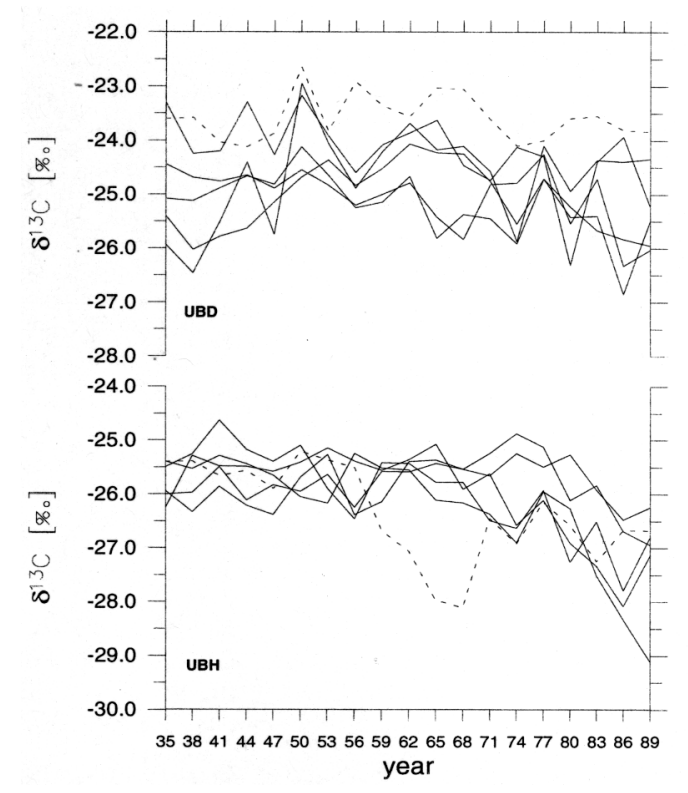

Fig. 2 Original $\delta^{13} \mathrm{C}$ data of the individual beech trees from the humid site UBH (lower graph) and the dry site UBD (upper graph). The trees represented by the dashed lines have not been considered for the calculation of the mean site curves

tree (dashed line). The $\delta^{13} \mathrm{C}$ series of the individual trees show hardly any common short term variations. However, the parallel decrease from 1977 to 1989 is striking. The difference in $\delta^{13} \mathrm{C}$ for the individual trees between the years of 1977 and 1989 is: UBH1: $-0.53 \%$, UBH2: $-3.16 \%$, $\mathrm{UBH} 3=-1.81 \%$, UBH4 $=-1.03 \%$, UBH5 $=-0.87 \%$, UBH6 $=-0.75 \%$. The mean difference is $-1.36 \%$ t $0.99 \%$. A measure of variation is the sensitivity which is defined as the average difference from one ring package to the next [that is $\frac{\sum_{i=1}^{n-1}\left|S_{i+1}\right|}{n-1}$ where $S_{i+1}=\left(\delta_{i+1}-\delta_{i}\right)$ and $\delta_{i}$ are the isotope values]. The sensitivity is low at the humid site UBH: $0.46 \% \pm 0.08 \%$ for the whole period and $0.40 \%$ $\pm 0.08 \%$ between 1935 and 1977 . Figure 2 (upper graph) shows the time course of $\delta^{13} \mathrm{C}$ for beech trees at the dry site UBD. The values range from $-26 \%$ to $-23 \%$. More similarities are apparent between the short term variations of individual trees than at the humid site, especially, if one tree is omitted (dashed line). Further, the sensitivity is higher $(0.58 \% \pm 0.19 \%)$.

\section{Ring width of individual trees}

The oldest rings of the six beech trees from the humid site UBH date from 1873, 1889, 1890, 1894, 1902 and 1903. Thus, the mean age of the oldest rings in 1989 was 97 years. In Fig. 3 (lower graph) non-normalised tree ring width for these trees is shown from 1900 to 1989 . Strong negative marker years are found in 1945 and 1948, and the general trend is slightly decreasing until 1960. Afterwards, ring width increases in roughly two steps, a small one in 1963 ( 5 from 6 trees reacting) and a large one in 1972 (all trees).

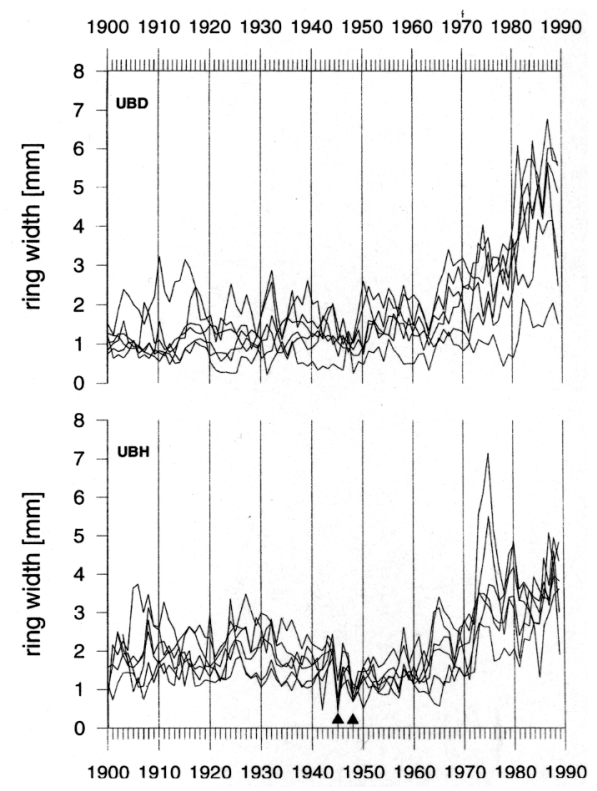

Fig. 3 Original ring width data of the six beech trees from the humid site UBH (lower graph) and the dry site UBD (upper graph). The arrows indicate two narrow rings occurring in all trees from UBH

At the dry site UBD the oldest rings are dated for 1848 , $1848,1855,1874,1880,1891$ and the mean tree age is 123 years. Therefore, the trees from this site are approximately 25 years older than the trees from the humid site. No trend is apparent in the first 60 years presented in Fig. 3 (upper graph). Then again ring width increases in two steps: one starting in 1963 and the other in about 1978. Thus both sites indicate a strong improvement of the growing conditions for the beech trees in the 1960s and1970s. The ring width is at least doubled compared to the earlier time period, from about $1.5 \mathrm{~mm}$ at both sites to about $4 \mathrm{~mm}$ at UBD and to $3.5 \mathrm{~mm}$ at $\mathrm{UBH}$.

\section{Mean site curves}

We calculated mean site $\delta^{13} \mathrm{C}$ curves for UBD and UBH. The two trees represented by the dashed lines in Fig. 2 were not considered for this calculation (for an unknown reason their isotopic signature differs clearly from the other trees). The same calculation was done for tree ring width, taking 3 year means as well to facilitate the comparison with the isotope data. In addition, it must be considered that the $\delta^{13} \mathrm{C}$ of atmospheric $\mathrm{CO}_{2}$, the source of the organic carbon, was not constant during the investigated period because of the input of isotopically light $\mathrm{CO}_{2}$ by fossil fuel consumption. Therefore, the $\delta^{13} \mathrm{C}$ of atmospheric $\mathrm{CO}_{2}$ decreased from $-6.8 \%$ in 1935 to $-7.8 \%$ in 1989 (Friedli et al. 1986; Keeling et al. 1989). This trend was not linear but the $\delta^{13} \mathrm{C}$ remained constant from 1935 to about 1950 and from then on decreased at a rate of approximately $0.25 \%$ per decade. We corrected our tree ring $\delta^{13} \mathrm{C}$ data to a constant $\delta^{13} \mathrm{C}$ in atmospheric $\mathrm{CO}_{2}$ using a spline fit calculated from the data 


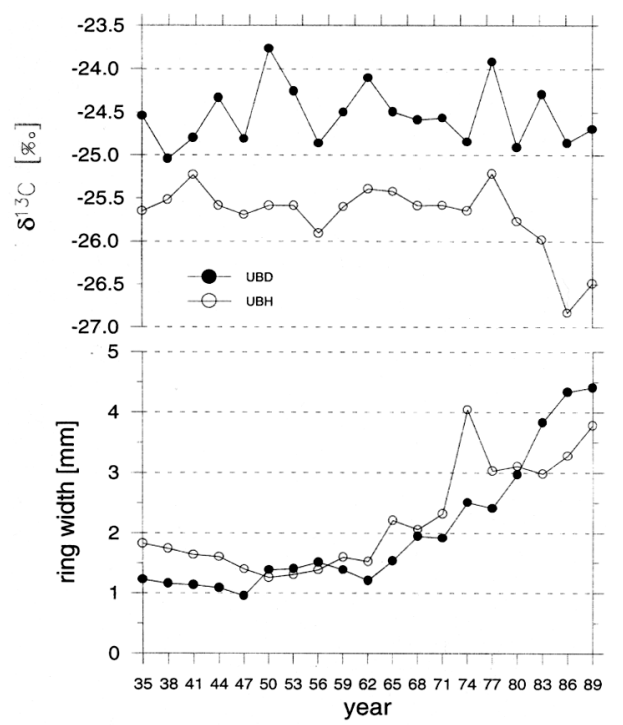

Fig. 4 Mean site curves of ring width (lower graph) and $\delta^{13} \mathrm{C}$ (upper graph) for the sites UBH and UBD. The isotope data have been corrected to a constant $\delta^{13} \mathrm{C}$ of atmospheric $\mathrm{CO} 2$ and linearly detrended

from Friedli et al. (1986) and Keeling et al. (1989). After this correction the tree ring $\delta^{13} \mathrm{C}$ series are slightly increasing. This trend is removed by a linear correction and the final result is shown in Fig. 4.

Regarding the humid site UBH, the main feature in Fig. 4 is the opposite course of tree ring width and $\delta^{13} \mathrm{C}$. A linear regression analysis between the two parameters yields $r=-0.71$ and a slope of $-0.46 \%$ in $\delta^{13} \mathrm{C}$ per $\mathrm{mm}$ ring width that is significant at $P<0.01$ (according to $F$-test). This correlation analysis between ring width and $\delta^{13} \mathrm{C}$ was also done for the individual trees; five from six trees have a negative correlation between ring width and $\delta^{13} \mathrm{C}$ whereas it is significant at $P<0.01$ for three trees. In contrast, the $\delta^{13} \mathrm{C}$ curve from the dry site UBD does not decrease at the end of the series though ring width similarly increases as it was observed at the humid site. Therefore, the correlation between $\delta^{13} \mathrm{C}$ and ring width that has been found for the humid site UBH does not hold for the site UBD (see Fig. 4). Further, the mean $\delta^{13} \mathrm{C}$ is higher at UBD compared to UBH and the sensitivity of the $\delta^{13} \mathrm{C}$ series is higher $(0.24 \%$ at $\mathrm{UBH}$ and $0.41 \%$ at UBD).

\section{Climatic correlations}

To determine the climatic significance of the mean $\delta^{13} \mathrm{C}$ site values we considered monthly data of temperature, precipitation and relative humidity using data from a number of weather stations in the Swiss Central Plateau (see Fig. 1). We made simple linear regression calculations correlating the $\delta^{13} \mathrm{C}$ data with all the possible combinations of months of length 1 to 12 . For instance, the periods with 4 months include January to April, February to May and so forth. We used the corrected isotope data as given in Fig. 4. For the dry site UBD the precipitation amount proved to have the

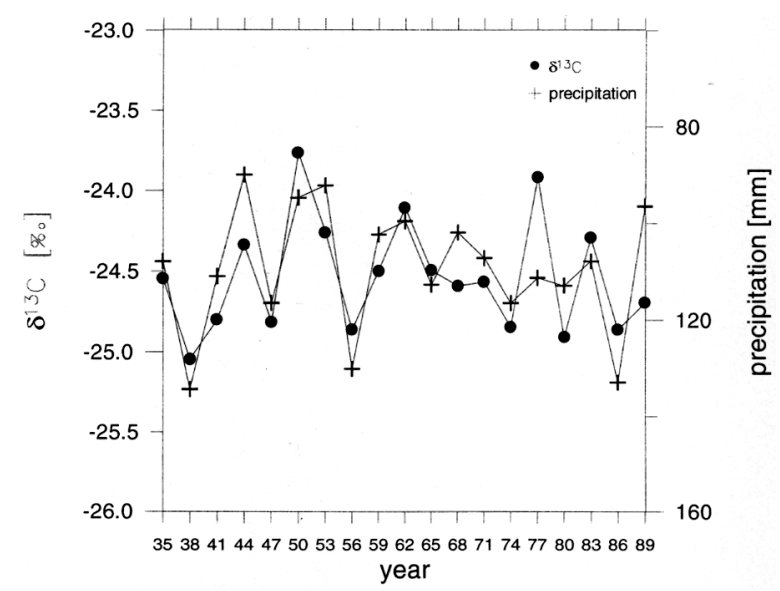

Fig. 5 Mean series of $\delta^{13} \mathrm{C}$ of the dry site $\operatorname{UBD}(-; y$-axis to the left) shown together with the mean precipitation amount of May+June+July using the data of seven weather stations of the Swiss Central Plateau indicated in Fig. 1 ( $+; y$-axis to the right; note the direction of the axis!)

strongest influence on the isotopic variations and the period that was best correlated is from May to July. This is a period of the growing season (but it is not the complete growing season because cellulose is also formed in August). When the data from the weather station are used which is nearest to the tree site (Burgdorf) the correlation coefficient between $\delta^{13} \mathrm{C}$ and the precipitation amount is $r=-0.67(P<0.01$ according to $F$-test $)$ and the slope of the regression equation is $-0.017 \%$ per $\mathrm{mm}$. When the precipitation data from all stations in Fig. 1 are averaged the correlation to precipitation is slightly improved $(r=-0.73)$. This result is shown in Fig. 5, proving a strong similarity between climate and the isotopic composition for the dry site UBD. In contrast, no significant correlation with climate exists for the humid site UBH. The correlation coefficient $r$ comparing $\delta^{13} \mathrm{C}$ and summer precipitation amount is -0.22 . At both sites neither temperature nor relative humidity are significantly correlated to $\delta^{13} \mathrm{C}$.

\section{Comparison with other sites in the Swiss Central Plateau}

In Fig. 6, the mean site curves of $\delta^{13} \mathrm{C}$ of four dry sites and of three humid sites are shown (location of sites given in Fig. 1), including the data from the two sites presented above. Each of the curves represents the mean of four to six trees and is calculated using the original, not corrected measurements. The variations in $\delta^{13} \mathrm{C}$ of the dry sites appear to be very similar and the pairwise correlation coefficients given in Table 1 confirm the visual impression. Most of the dry sites are significantly correlated to each other. The exception is the HUD site but this can be explained by the slightly decreasing long term trend. The short term variations at HUD are in fact very similar to the other dry sites. This will be substantiated below. All of the $\delta^{13} \mathrm{C}$ curves of the humid sites are more negative than the dry sites by 1 to $2 \%$ and the sensitivity is lower. Never- 


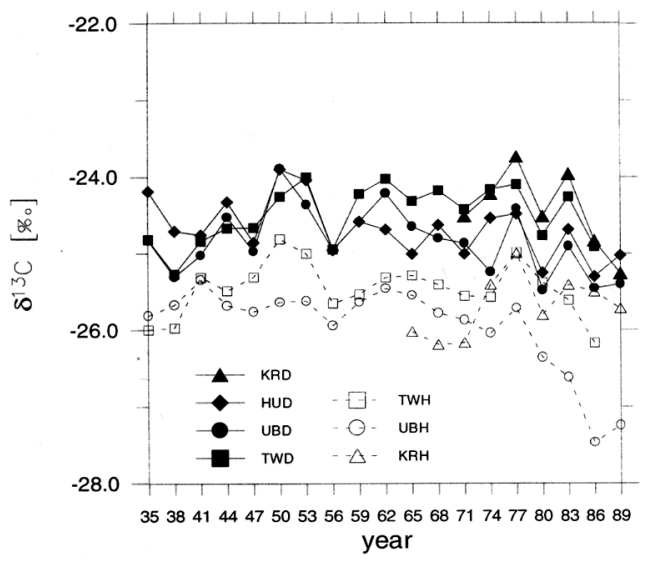

Fig. $6 \delta^{13} \mathrm{C}$ site values of all sites. Each curve represents the mean of 4 to 6 beech trees from one site (original data). Dry sites are indicated by filled symbols and humid sites by open symbols

theless there are also similarities between the dry and the humid sites (see Fig. 6 and Table 1) which appear to be caused by low frequency variations ( $>10$ years). Complementary to the correlation analysis one might also look at the behaviour of the curves in more detail. There are periods where the $\delta^{13} \mathrm{C}$ of all sites changes in the same direction, e.g. 1944-1947, 1953-1959, 1974-1977. During these periods the influence of the climate is probably exceptionally strong. Clearly an outstanding event is the declining trend at the end of the series of UBH.

The close similarity of the $\delta^{13} \mathrm{C}$ variations at the dry sites can be made still more evident by the following calculation. The correction for the changing $\delta^{13} \mathrm{C}$ in atmospheric $\mathrm{CO}_{2}$ is applied and the curves are linearly detrended (as explained above). Then the mean $\delta^{13} \mathrm{C}$ value of the whole investigated period is calculated for every site and subtracted from the individual $\delta^{13} \mathrm{C}$ values. The resulting curves all have a mean value of zero and may therefore be termed as anomalies (Fig. 7). After these operations the series from HUD is also significantly correlated to the other dry sites. Due to the close similarity of the $\delta^{13} \mathrm{C}$ variations not only is UBD correlated to summer precipitation (as shown above) but also the other dry sites (see Saurer et al. 1995a). Additionally, HUD and TWD are significantly related to summer temperature and the slope of the linear fit to the data is $0.35 \%$ per ${ }^{\circ} \mathrm{C}$. This coefficient is in good agree-

Table 1 Correlation coefficients $r$ comparing the mean site $\delta^{13} \mathrm{C}$ curves to each other (original data). [Different shadings have been used to characterize the types of correlations. Dark: dry sites versus dry sites; medium: dry sites versus humid sites; light: humid sites versus

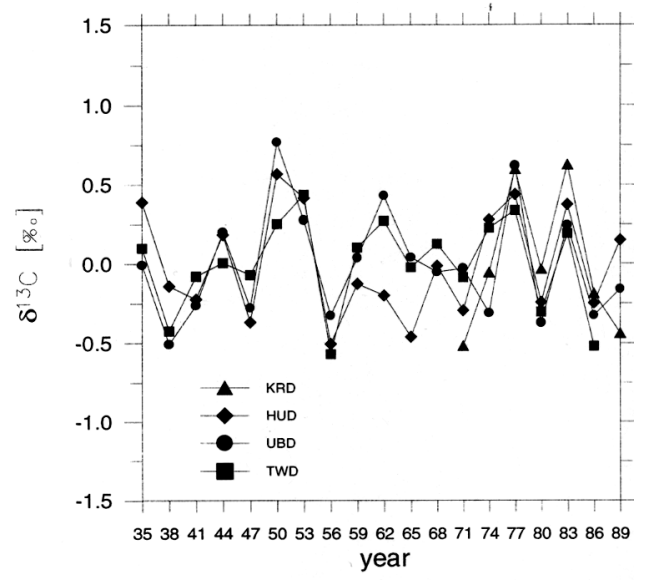

Fig. $7 \delta^{13} \mathrm{C}$ anomalies of the dry sites after correction to a constant $\delta^{13} \mathrm{C}$ of atmospheric $\mathrm{CO}_{2}$, linear detrending and subtraction of the means

ment with values in the literature: Lipp et al. (1991), for instance, report a value of $0.33 \%$ per ${ }^{\circ} \mathrm{C}$.

\section{Discussion}

The $\delta^{13} \mathrm{C}$ series of the dry sites reveal a strong spatial coherence, indicating the presence of a common mechanism controlling the ${ }^{13} \mathrm{C}$-content in this area. An external cause and not a local or plant physiological factor appears to be the main determinant of the isotope variations. This external cause was found to be the climate, more precisely the precipitation amount of the summer months May, June and July, thus confirming earlier findings (Dupouey et al. 1993; Leavitt and Long 1988; Saurer et al. 1995a). Water conditions appear to be more important than temperature to explain the carbon isotope variations in tree rings of beech, at least at dry sites. This result is in agreement with theoretical considerations: water conditions should have a more direct impact on ci, the main variable in the Farquharmodel, than temperature (see Introduction). All the same, correlations between $\delta^{13} \mathrm{C}$ and temperature could be the result of a correlation between temperature and precipitation depending on the type of climate. We found that the short term variations ( $<10$ years) are mainly climatically

humid sites]. Significance levels according to $F$-test are given in parentheses: $P<0.05^{*}, P<0.01^{* *}$ (not indicated if not significant). The investigated period is indicated for each site

\begin{tabular}{|c|c|c|c|c|c|c|}
\hline & $\begin{array}{l}\text { HUD } \\
(1934-1990)\end{array}$ & $\begin{array}{l}\text { TWD } \\
(1934-1987)\end{array}$ & $\begin{array}{l}\text { KRD } \\
(1970-1990)\end{array}$ & $\begin{array}{l}\text { UBH } \\
(1934-1990)\end{array}$ & $\begin{array}{l}\text { TWH } \\
(1934-1987)\end{array}$ & $\begin{array}{l}\text { KRH } \\
(1964-1990)\end{array}$ \\
\hline UBD (1934-1990) & $0.73(* *)$ & $0.64(* *)$ & $0.76(*)$ & $0.63(* *)$ & $0.70(* *)$ & 0.06 \\
\hline HUD (1934-1990) & & 0.40 & 0.74 & $0.53(*)$ & 0.44 & 0.38 \\
\hline TWD (1934-1987) & & & $0.88(*)$ & 0.24 & $0.64(* *)$ & 0.15 \\
\hline KRD (1970-1990) & & & & 0.73 & 0.77 & 0.59 \\
\hline UBH (1934-1990) & & & & & $0.55(*)$ & 0.23 \\
\hline TWH (1934-1987) & & & & & & 0.08 \\
\hline
\end{tabular}


determined. This result follows from the improvement of the coherence when the long term trends are removed, that is when the $\delta^{13} \mathrm{C}$ curves are linearly detrended (Fig. 7). Nevertheless, moisture conditions also influence the carbon isotope ratio in the long run. All the mean values from the dry sites are more positive than the values from the humid sites (Fig. 6), which is another proof of the climatic relevance of $\delta^{13} \mathrm{C}$. The statistical analysis showed that a period of the growing season has the strongest effect on the isotopic variations. This is not unexpected, of course, but still adds to the credibility of the results. This period is from May to July. It is noteworthy that Lipp et al. (1991) found the best correlation between the climate of August and $\delta^{13} \mathrm{C}$ in late-wood of fir. In our study we did not separate earlyand late-wood (because a visual distinction is hardly possible for beech), and this may explain why we find the best correlation with an earlier period of the growing season. The $\delta^{13} \mathrm{C}$ of early-wood is largely determined by previous year carbohydrates (Hill et al. 1995) and therefore the use of whole rings might disturb the climate-isotope relationship. When three rings are pooled, however, as was done in our study, the influence of this mixing effect is reduced by a factor of approximately three and is probably negligible.

The good correlation between the $\delta^{13} \mathrm{C}$ curves of the dry sites is remarkable in view of the strongly differing behaviour of the tree ring width series at the different sites. Ring width at the dry site UBD increased during the last 20 years of the record (Figs. 3, 4) whereas at the other dry sites, HUD and TWD, ring width was more or less constant during the whole investigated period with either low (HUD) or high sensitivity (TWD) (Saurer et al. 1995a). Ring width does not carry much climatic information at these sites. Though the sites are characterized as relatively dry, the climate is temperate-moist in Switzerland. Apparently, the isotope curves of the different dry sites are hardly affected by ring width variations, i.e. the local growth conditions have only a minor influence on the isotopic composition. The carbon isotope analysis therefore is a powerful tool for climatic reconstruction - as it concerns the dry sites. Unfortunately, the beech trees at the humid sites are not well correlated to climate. At UBH, the lack of any correlation to climate is not astonishing for the period from 1935 to 1977 because there are no distinct variations. For the other humid site, TWH, a slight influence of the precipitation amount was found (Saurer et al. 1995a). We can assume that the trees hardly suffer from drought stress in years with low precipitation. Thus the stomata do not have to close and, as a consequence, the isotope ratio does not increase. Further, the negative result from the correlation analysis at $\mathrm{UBH}$ means that the decrease in $\delta^{13} \mathrm{C}$ at the end of the series can not be explained by the climate. Instead, based on the results from Fig. 4 we conclude that this effect is caused by the amelioration of growth conditions (due to clearing of part of the trees) reflected in the increase in ring width. In contrast to the dry sites, there is a correlation between $\delta^{13} \mathrm{C}$ and ring width for this site.

Therefore, we have to address the following important question. How does a change in tree growth influence the carbon isotope discrimination? We will discuss this problem in theory as well as referring to results in the literature. According to the commonly used model (Farquhar et al. 1982) there is no generally valid answer to the above question. The cause for the change in growth must be looked at:

1. Growth and hence ring width may be increased by enhanced photosynthetic capacity while stomatal conductance is kept relatively constant. ci is then lowered and $\delta^{13} \mathrm{C}$ becomes more positive.

2. A raise in stomatal conductance may be observed along with an increase in growth. The supply of $\mathrm{CO}_{2}$ and the assimilation rate per unit leaf area increases in this case and $\delta^{13} \mathrm{C}$ becomes more negative.

3. Finally, ci may be kept constant if the plant varies stomatal conductance and photosynthetic capacity in common (Wong et al. 1979).

When a tree is exposed to more light, for instance, (1) is true. In a laboratory experiment with young Picea abies trees, Broadmeadow and Griffiths (1993) varied photosynthetic photon flux density from about $100 \mu \mathrm{mol} \mathrm{m} \mathrm{m}^{-2} \mathrm{~s}^{-1}$ to $600 \mu \mathrm{mol} \mathrm{m} \mathrm{m}^{-2} \mathrm{~s}^{-1}$ and found a concurrent increase of $\delta^{13} \mathrm{C}$ in the shoots of about 5\%o $( \pm 1 \%$ depending on physiological conditions of the trees). In this case the correlation between biomass production and the $\delta^{13} \mathrm{C}$ is positive. For adult trees this light dependence of the isotope fractionation is reflected in a gradient with height. For example, Schleser and Jayasekera (1985) found a $\delta^{13} \mathrm{C}$ value $2.3 \%$ higher in leaves on top of the canopy of an isolated lime (Tilia) tree compared to the leaves low in the canopy, resulting in a gradient of $0.16 \% \mathrm{~m}^{-1}$. The above influences are most severe for young trees. A juvenile effect on $\delta^{13} \mathrm{C}$ has been reported in the literature (Francey et al. 1985), i.e. increasing $\delta^{13} \mathrm{C}$ values of typically $2 \%$ in the first years of a tree's life. Thus, this trend is consistent to what can be expected from a tree increasingly exposed to light during the grow up to the same canopy height as its adjacent individuals.

Enhanced growth along with increased stomatal conductance (2), should hold, for instance, when drought stress is reduced. Here we expect a negative correlation between growth and $\delta^{13} \mathrm{C}$. In most tree ring studies where a correlation between ring width and $\delta^{13} \mathrm{C}$ was found the correlation was negative which suggests that the mechanism (2) was responsible for the changes in ring width. Leavitt and Long (1988) studied pinyon pine trees from nine sites in Arizona and found that correlations between $\delta^{13} \mathrm{C}$ and ring width indices were uniformly negative. Mazany et al. (1980) and Tans and Mook (1980) found similar results. Mazany et al. (1980) studied Ponderosa pine and white fir from sites in New Mexico and concluded that warm and dry years cause narrow rings and high $\delta^{13} \mathrm{C}$ values, probably due to drought stress. McNulty and Swank (1995) report a negative correlation between $\delta^{13} \mathrm{C}$ and basal area growth for white pine trees (Pinus strobus). This result is particularly interesting because the study was conducted at a location (North Carolina, USA) which receives a very high rate of precipitation (1800 mm per year). Further, air pollutants can cause a negative correlation between growth and $\delta^{13} \mathrm{C}$. Martin and Sutherland (1990) found reduced ring width 
for Douglas-fir in periods with high $\mathrm{SO}_{2}$ emissions from a nearby smelter accompanied by high $\delta^{13} \mathrm{C}$ values. It seems that a large variety of stresses lead to increased $\delta^{13} \mathrm{C}$ values and - since stress usually reduces growth - to a negative correlation between growth and $\delta^{13} \mathrm{C}$. This rule may even hold in contradiction to the Farquhar-model as was found in ozonated birch cuttings (Betula pendula; Saurer et al. 1995b): $\delta^{13} \mathrm{C}$ increased under ozone although water use efficiency was reduced (i.e. ci increased). It was assumed that a change in the ratio of the carboxylating enzymes (phosphoenol pyrovate carboxylase and rubisco) was the cause, which was interpreted as an acclimation response to ozone stress.

Can the above findings be applied to the negative correlation between ring width and $\delta^{13} \mathrm{C}$ found at the humid site $\mathrm{UBH}$ and the insensitivity of $\delta^{13} \mathrm{C}$ to ring width variations at the dry sites? Most likely ring width at UBH increased in the 1960s and 1970s due to the clearing of part of the trees which improved the growth conditions for the remaining trees in terms of exposition to light and nutrition. From the above findings we would conclude that an abrupt increase in growth due to more light should be accompanied by increasing $\delta^{13} \mathrm{C}$ values (see 1). Yet, what we find at the site UBH is just the opposite. Moisture conditions might also change as a result of the clearing of trees but this should be neglected at this humid site. A possible explanation for the isotopic behaviour has been indicated in the last paragraph. Just as stress usually increases $\delta^{13} \mathrm{C}$, an amelioration of growth conditions can be expected to decrease $\delta^{13} \mathrm{C}$. The question then remains why ring width variations at the dry sites do not affect $\delta^{13} \mathrm{C}$. Here the mechanism (3) seems to be valid: ci is kept constant which can be considered a homeostatic behaviour. We are aware that at present it is not possible to make a causal link between ring width variations and isotope variations. Yet, this would be very helpful to improve the climatic reconstruction based on isotopes. Regarding the interpretation of $\delta^{13} \mathrm{C}$ in fossil wood, the problem arises that no information is available about site conditions. Tree ring width variations are influenced by local growth conditions. Therefore, the combined analysis of ring width and isotope data will yield substantially more palaeoclimatic information than the isolated study of the two parameters.

Acknowledgements Parts of this study were financed through the NFP-31 programme 'Climate Changes and Natural Disasters' of the Swiss National Fund.

\section{References}

Brenninkmeijer CAM (1983) Deuterium, oxygen-18 and carbon-13 in tree rings and peat deposits in relation to climate. Thesis, University of Groningen, The Netherlands
Briffa KR, Jones P, Schweingruber F (1988) Summer temperature pattern over Europe: a reconstruction from 1750 A.D. based on maximum latewood density indices in conifers. Quat Res 30: $36-52$

Broadmeadow MSJ, Griffiths H (1993) Carbon isotope discrimination and the coupling of $\mathrm{CO}_{2}$ fluxes within forest canopies. In: Ehleringer JR, Hall AE, Farquhar GD (eds) Stable isotopes and plant carbon-water relations. Academic Press, San Diego, pp 109-129

Dupouey JL, Leavitt S, Choisnel E, Jourdain S (1993) Modeling carbon isotope fractionation in tree rings based on effective evapotranspiration and soil water status. Plant Cell Environ 16: 939-947

Ellenberg H, Kloetzli F (1972) Waldgesellschaften und Waldstandorte der Schweiz. Swiss Federal Institute for Forest, Snow and Landscape Research, Mitteilungen 48(4)

Farquhar GD, O'Leary MH, Berry JA (1982) On the relationship between carbon isotope discrimination and the intercellular carbon dioxide concentration in leaves. Aust J Plant Physiol 9: 121-137

Francey RJ, Farquhar GD (1982) An explanation of ${ }^{13} \mathrm{C} / 12 \mathrm{C}$ variations in tree rings. Nature 297: 28-31

Francey RJ, Gifford RM, Sharkey TD, Weir B (1985) Physiological influences on carbon isotope discrimination in the huon pine (Lagarostrobos franklinii). Oecologia 44: 241-247

Friedli H, Loetscher H, Oeschger H, Siegenthaler U, Stauffer B (1986) Ice record of the ${ }^{13} \mathrm{C} / 12 \mathrm{C}$ ratio of atmospheric $\mathrm{CO}_{2}$ in the past two centuries. Nature 324: 237-238

Hill SA, Waterhouse JS, Field EM, Switsur VR, Aprees T (1995) Rapid recycling of triose phosphates in oak stem tissue. Plant Cell Environ 18: $931-936$

Keeling CD, Bacastow RB, Carter AF, Piper SC, Whorf TP, Heimann M, Mook WG, Roeloffzen H (1989) A three-dimensional model of atmospheric $\mathrm{CO}_{2}$ transport based on observed winds: 1. Analysis of observational data. Geophys Monogr Am Geophys Union 55: $165-236$

Leavitt SW, Long A (1988) Stable carbon isotope chronologies from trees in the southwestern United States. Global Biogeochem Cycles 2: $189-198$

Lipp J, Trimborn P, Fritz P, Moser H, Becker B, Frenzel B (1991). Stable isotopes in tree ring cellulose and climatic change. Tellus 43B: $322-330$

Martin B, Sutherland EK (1990) Air pollution in the past recorded in width and stable carbon isotope composition of annual growth rings of Douglas-fir. Plant Cell Environ 13: 839-844

Mazany T, Lerman JC, Long A (1980) Carbon-13 in tree-ring cellulose as an indicator of past climates. Nature 287: 432-435

McNulty SG, Swank WT (1995) Wood $\delta^{13} \mathrm{C}$ as a measure of annual basal area growth and soil water stress in Pinus strobus forest. Ecology 76: 1581-1586

Saurer M, Siegenthaler U, Schweingruber F (1995a) The climatecarbon isotope relationship in tree rings and the significance of site conditions. Tellus 47B: 320-330

Saurer M, Maurer S, Matyssek R, Landolt W, Günthardt-Georg MS and Siegenthaler U (1995b) The influence of ozone and nutrition on $\delta^{13} \mathrm{C}$ in Betula pendula. Oecologia 103: 397-406

Schleser GH, Jayasekera R (1985) $\delta^{13} \mathrm{C}$ - variations of leaves in forests as an indication of reassimilated $\mathrm{CO}_{2}$ from the soil. Oecologia 65: 536-542

Schweingruber F (1988) Tree rings. In: Basics and applications of dendrochronology. Reidel, Dordrecht

Tans PP, Mook WG (1980) Past atmospheric $\mathrm{CO}_{2}$ levels and the ${ }^{13} \mathrm{C} /$ ${ }^{12} \mathrm{C}$ ratios in tree rings. Tellus 32B: $268-283$

Wong SC, Cowan IR, Farquhar GD (1979) Stomatal conductance correlates with photosynthetic capacity. Nature 282: 424-426 